\title{
Adaptation of Water Resources Management to Changing Climate: The Role of Intensity-Duration-Frequency Curves
}

\author{
Latifa A. Yousef and Taha B. M. J. Ouarda
}

\begin{abstract}
Climate change influences the intensity and frequency of precipitation events, causing the need for new strategies in water resources management. This paper presents the role of hydrology in helping to establish these new strategies, focusing specifically on rainfall intensity-duration-frequency (IDF) curves. A methodology is proposed for developing IDF curves using covariates of climate indices. A case study is presented for the station of Riviere Heva in Quebec, Canada. The IDF models incorporating climate indices exhibit significant improvements in terms of goodness of fit over the traditional models, forming the conclusion that design standards for water-related structures must be updated to incorporate climate change.
\end{abstract}

Index Terms-Climate change, water management, hydrology, hydro-meteorological modeling, intensity-duration-frequency curves.

\section{INTRODUCTION}

The leading cause of climate change is the emission of greenhouse gases, which include carbon dioxide, nitrous oxide, methane, ozone and water vapor. These gases can be produced naturally, or emitted as a result of human activities, causing global warming. The reasons for why climate change has become an important concern were listed in detail by Smith et al. (2001) [1]. They discuss how the increase in the mean global temperature can produce effects that are beneficial to some regions, and negative to others. A report produced by the intergovernmental panel on climate change (IPCC) [2] gave proof of climate change via direct observations throughout recent years. Some of the evidence they listed is higher rises in temperature, more frequent hot days and nights, widespread melting of ice caps and glaciers, the rise of the global average sea level, increased droughts, and higher frequency of occurrence of extreme storm events. It is agreed upon and recognized that if greenhouse gas emissions continue at their current rates, or increase, the world will witness changes that are predicted to be more severe than those observed in the twentieth century. An example of an important sector influenced by climate change

Manuscript received April 25, 2014; revised August 1, 2014. This work was supported by the Masdar Institute of Science and Technology.

L. A. Yousef is with the Masdar Institute of Science and Technology, Abu Dhabi, UAE (e-mail: layousef@ masdar.ac.ae).

T. B. M. J. Ouarda was with the Department of Statistical Hydrology, University of Quebec, Canada. He is now with the Department of Chemical and Environmental Engineering, Masdar Institute of Science and Technology, United Arab Emirates (e-mail: touarda@masdar.ac.ae). is agriculture.

The hydrologic system impacts and is impacted by climate change. Changes in rainfall patterns have direct effects on the timing and magnitude of floods and droughts, and cause alteration of groundwater recharge rates. Vegetation pattern and growth rates and the changes in soil moisture regime are also be impacted. Availability of water resources is expected to have impacts on river flow, which in turn affects navigation, power generation and wetland and ecosystem conservation. The availability of water resources will require change in water policy, in food production and food security and might cause national and international tension [3].

Water management encompasses all activities related to the maintenance and improvement in the state of water resources. In many regions around the world the water available is polluted, rendering it incompatible for many applications, or requiring expensive treatment to be put to use [4]. The increase in rates of urbanization, industrialization and agricultural productivity has intensified pressure on available water resources, in addition to the increase in droughts. Water-related infrastructure in urban areas represents very large economic value. It also has an enormous impact on the hydraulic, environmental, economic and social function of any city [5].

It is generally agreed upon that changes in policies and resources management are now required, in order to both combat and adapt to the variability being witnessed as a consequence of climate change. Climate change has caused variability in the frequency and magnitude of precipitation extremes, which affects the design standards for some hydrological structures. This paper discusses the effects of climate change on the hydrological analysis step of water management, focusing specifically on how to integrate climate change in formulation of intensity-duration-frequency (IDF) curves. With the attention that has been given in recent years to advances in hydrological modeling and the incorporating of covariates, IDF curves have had numerous studies conducted to develop them with these considerations [6]-[9].

The main objective of the study presented in this paper is to provide a basis for adjustments of water management and policies to future climate scenarios by formulating IDF curves which provide better predictions of rainfall intensities considering the effects of climate oscillations as variables on precipitation. In order to achieve this, it is necessary to develop the appropriate methodology which incorporates the new variables in IDF modeling. Once the methodology is developed, the verification of the models is done by taking a case study of one station in Canada and analyzing the results of the developed models. 


\section{LITERATURE REVIEW}

\section{A. Effects of Climate Oscillations on Precipitation}

A climate oscillation is a type of climate pattern that recurs as a cycle in global or regional climate. These fluctuations in atmospheric temperature, sea surface temperature, precipitation or other parameters can be quasi-periodic, often occurring on inter-annual, multi-annual, decadal, multidecadal, century-wide, millennial or longer timescales. It is theorized that origins of climate oscillations could be related to astronomical factors and modes of heat distribution between the ocean-atmosphere climate system [10]. Examples of known or proposed climate oscillations include the atlantic multidecadal oscillation, the Southern Oscillation and the Pacific Decadal Oscillation.

The atlantic multidecadal oscillation (AMO) is a near-global scale mode of observed multidecadal climate variability with alternating warm and cool phases over large regions in the Northern Hemisphere. It has been linked to rainfall variability in a number of regions in the world [11]. The southern oscillation (SO) is the atmospheric component of El Niño. It is an oscillation in surface air pressure between the tropical eastern and the western Pacific Ocean waters. Ropelewski and Halpert (1986) [12] investigated North American precipitation patterns associated with the $\mathrm{El}$ Niño/Southern oscillation (ENSO). Areas around the Great Basin and the Gulf of Mexico showed a consistent ENSO-related precipitation signal. The Pacific decadal oscillation (PDO) is a leading mode of multi-decadal variability in SSTs in the extra-tropical North Pacific. Positive phases of the PDO are associated with climatic conditions that include decreased winter precipitation in the northwest and higher precipitation in the southwest. Conditions reverse during negative PDO phases [13].

\section{B. Integration of Climate Change into Water Management}

Numerous studies have been conducted worldwide to assess the effects of climate change on water resources specific to a certain region, and how to adapt water management to these effects. A study was conducted to assess the impact of climate change on river flows in the Rhine Basin, and the appropriate scenarios to be taken [14]. Balancing the required actions against economic cost and the existing uncertainties in the climate change scenarios, a policy of 'no regret and flexibility' in water management planning and design was recommended, where anticipatory adaptive measures in response to climate change impacts are undertaken in combination with ongoing activities.

Climate simulations were produced in a study by Christensen et al. (2004) [15] for the Colorado River basin to assess the impacts of climate change on the water resources of the area. The river basin is characterized by its high demand compared to supply, and the domination of snow accumulation over runoff generation. The results of the study indicated that water delivery and reservoir evaporation from the river basin system would exceed inflows to the reservoir, therefore creating a shortage in supply compared to demand. The output of hydropower was also projected to significantly decrease.

Werritty (2002) [16] studied the increased variability in the hydroclimate of Scotland. It is predicted that the country will become wetter than it is at present, and moderate flooding will increase in severity over the next few decades. As a response to these findings, it was recommended that the precautionary principle be adopted, in addition to the design of new water management plans taking into account sensitivity to possible climate changes, and exhibiting robustness in adapting to these changes.

The water supply industry in England responded to the pressures they faced as a result of predictions that climate change will decrease water availability [17]. They released their draft water resources management plans (dWRMP) in 2008, following guidelines set by Environment Agency. These plans provided projections of the future balance between supply and demand in each company water resource zone, together with plans for ensuring an "adequate", balance between supply and demand. The plans included requirements that water companies account explicitly for the implications of climate change on resource zone deployable output by assessing the implications of climate change on river flows and groundwater recharge.

A European project under the title of "NeWater", which refers to "New methods for adaptive water management under uncertainty", developed a conceptual framework for understanding and a comprehensive methodology for analysis and implementation of transitions to adaptive water management [18]. NeWater devoted much attention to the establishment of integration between social, natural and engineering sciences and to the bridging of the science-policy gap. It also advocated innovation in research approaches in order to conduct analysis and achieve understanding of human-technology-environment systems.

Beniston, Stoffel, Clarvis and Quevauviller (2014) [19] assessed the effects of the climate change on water in the region of the Alps. Snow and ice are important factors of the hydrologic cycle, and vital contributors to the freshwater resources of this region, hydropower generation and irrigation. Climate induced changes in precipitation and temperature impact both the quantity and timing of water available across these different sectors, resulting in socio-economic effects. The study recognized that traditional management approaches were inadequate to cope with the variability occurring in the region's water supply, and that adaptability of current frameworks for managing water resources and hazards to future climate change impacts should be assessed.

\section{Role of Hydrology in Water Management}

Despite the ultimate decisions in management of water resources being based on political, legal, economic and social factors, the foundation is based on the science of hydrology. Hydrology studies the movement, distribution and quality of water. It describes and predicts the spatial and temporal variations of water substances, in addition to the processes involved in water movement. It is built upon the fundamental sciences of mathematics, physics, chemistry and biology. Statistical hydrology analyzes the statistical properties of hydrologic records, such as rainfall and river flow, in order to project future hydrologic phenomena [20]. An important use for this science is the assessment of the frequency of occurrence for relatively uncommon events. 


\section{Climate Change and Extreme Precipitation Events}

Changes in climatic extremes gained attention in the early 1990's [21]. With the increase in anthropogenically warmed climate, extreme precipitation events are projected to become more common. In the numerous studies that studied current and future modeled precipitation trends, a consistent result was variations in precipitation intensity, with the intensity of extreme events increasing [22]-[24].

Kharin, Zwiers, Zhang and Hegerl (2007) [25] found in their study on temperature and rainfall extremes that, with the exception of northern polar latitudes, relative changes in the intensity of precipitation extremes generally exceeded relative changes in annual mean precipitation, particularly in tropical and subtropical regions. A study on extreme precipitation in central and south Asia found disproportionate trends in extreme precipitation, and a significant trend was detected for the amount of rainfall on very wet days [26].

The potential effects of climate change on rainfall extremes, which are an integral part of the design of water management regulations and structures, are of particular concern, since changes in extremes may be larger than changes in average estimates [14]. An example of an application in which modeling of precipitation extreme events is key is drainage modeling. Despite the important relationship between them, the number of studies assessing the impacts of extreme events on urban drainage are limited [27]. The time-scales at which these events are described at are important, to assess whether the projections are relevant. Grum, Jorgensen, Johansen and Linde (2006) [28] concluded in their study of the impact of climate change on urban drainage that extreme precipitation events affecting urban drainage and causing flooding would become more frequent, therefore requiring changes in the design methodology for drainage systems.

One danger established in the study of Allan and Soden (2008) [29] was that the observed amplification of precipitation extremes was found to be larger than what models predicted, indicating that projections of variations in extreme rainfall caused by anthropogenic global warming were underestimated. Lenderink and Van Meijgaard (2008) [30] found that in the Netherlands, one-hour precipitation extremes increased twice as fast as expected from traditional relationships with temperature. Impacts resulting could take the form of local flooding, erosion and water damage. This would have severe implications on water structures and management strategies. With rainfall characteristics being used to design water management infrastructures, reviewing and updating rainfall characteristics (i.e., IDF curves) for future climate scenarios is necessary [8]. In order to represent hydro-meteorological variables appropriately, the reality of the impact of climate change on rainfall extremes must be properly addressed.

\section{E. Intensity-Duration-Frequency Curves}

Intensity-duration-frequency (IDF) relationships of rainfall are one of the most commonly used tools for planning and designing water resources projects. IDF relationships are a source of a great deal of useful information on rainfall and for the determination of "design storms", which is the usual term given to the rainfall event used for the design of a project or structure. The use of IDF relationships dates back to as early as the 1930's [31]. The generated IDF relationships are often represented graphically in the form of curves, with the axes of the graphs representing the intensity and duration of rainfall events, and each curve representing a specific return period.

IDF curves have been developed in many regions of the world, such as the United States [32] and Canada [33], and Italy [34]. IDF models for rainfall were developed recently in Saudi Arabia for the areas of Najran and Hafr Albatin [35].

\section{THEORETICAL BACKGROUND}

\section{A. IDF Relationship Formulation}

The basic principle behind the IDF relationship is finding how to relate the intensity of a rainfall event and its duration to its expected frequency. Precipitation intensity is the depth of rainfall per unit of time, and is usually expressed in the units of $\mathrm{mm} / \mathrm{hr}$ and $\mathrm{in} / \mathrm{hr}$. The average intensity is frequently applied, which is expressed as the rainfall depth for a particular precipitation event divided by the duration of that event. The frequency is often described in terms of return period, which is the average period of elapsed time between rainfall events that are equal to or more than the magnitude of design. The return period is the inverse of the annual probability of exceedance of an event. The return periods usually represented are for 2, 5, 10, 25, 50 and 100 years [35].

Koutsoyiannis, Kozonis and Manestas (1998) [36] proposed a generalized formulation of the IDF relationship, which exhibits advantages over the previously proposed formulations in the literature. Koutsoyiannis' generalized IDF relationship has been incorporated into many studies on areas all over the world. One such example was conducted for rainfall in Ghana [37], where the general method (referred to as the global method in this work) was applied. Ground and satellite data were combined to provide the best possible IDF spatial coverage and duration ranges, in addition to minimizing errors. The generalized IDF methodology was applied in Greece, using a series of maximum daily rainfall from a meteorological station in Athens [20].

The generalized IDF relationship can be expressed as follows:

$$
i=\frac{a(T)}{b(d)}
$$

where $T$ is the return period, and $d$ is the duration. One of the advantages of this form is how $i$ has a separate functional dependence on $T$ and $d$. The function $b(d)$ is usually described in the following form:

$$
b(d)=(d+\theta)^{\eta}
$$

where $\theta$ and $\eta$ are non-negative coefficients.

\section{B. Probability Distribution Functions}

IDF studies examine and test a variety of probability distributions, incorporating the distributions which provide the best fit for the studied data. Koutsoyiannis et al. (1998) gave alternative distribution functions that can be 
incorporated with the general IDF relationship, such as the Generalized Extreme Value (GEV) distribution, the Gumbel distribution and the Pareto distribution. The distribution adopted in this study is the Gumbel.

\section{Parameter Estimation}

Once the appropriate probability distribution is selected for the IDF formula, the unknown parameters must be determined. Koutsoyiannis, Kozonis and Manestas (1998) [36] detail a technique for estimating the parameters of the general IDF relationship named the one-step least squares method, which estimates all the parameters of both functions $a(T)$ and $b(d)$ in one step, minimizing the total square error of the fitted IDF relationship to the data. Due to the convenience, robustness and reliability of this method, it is selected for use in this study.

An empirical return period is assigned to each intensity value using the Gringorten formula, for which the calculations involve assigning a rank to each intensity value according to its position in a descending order of the intensity values for each duration group. The modeled intensity incorporating the calculated return periods are then found. The corresponding error is then modeled as follows:

$$
e_{j l}=\ln i_{j l}-\ln \widehat{i_{j l}}=\ln \left(\underset{\hat{i}_{j l}}{\hat{j}_{l}}\right)
$$

The logarithmic transformation is used to maintain balance among the errors of the intensities, given that the greater durations have lower errors than the lower durations.

The overall mean square error is found as follows:

$$
e^{2}=\frac{1}{k} \sum_{j=1}^{k} \frac{1}{n_{j}} \sum_{l=1}^{n_{j}} e_{j l}^{2}
$$

where $k$ is the number of duration groups included.

The estimation of the four parameters then becomes an optimization problem, with various techniques available that can be used. The optimization process can be defined as follows:

$$
\text { minimize } e=f(\lambda, \psi \quad \theta \quad \lambda)
$$

\section{IDF CURVE FORMULATION WITH COVARIATES OF Climate INDICES}

\section{A. Model Formulation}

The formulation of a climate oscillation incorporating general IDF model involves making a number of the parameters dependent on covariates. Not all parameters of the model need to be made covariate-dependent. El Adlouni and Ouarda (2009) [38] incorporated covariates into the parameters of the GEV distribution function, where they built models that express the location and scale parameters as being covariate-dependent, either linearly or quadratically.

The methodology proposed in this study is applicable to the general IDF relationship incorporating any of the previously listed probability distribution functions. Due to the choice of the Gumbel distribution for one of the case studies performed in this work, the example of a covariate-incorporating model is shown as follows, taking non-stationarity to be in both of the Gumbel parameters:

$$
i=\lambda_{t} \frac{\psi_{t}-\ln \left[-\ln \left(1-\frac{1}{T}\right)\right]}{(d+\theta)^{\eta}}
$$

where $\lambda_{t}$ and $\psi_{t}$ are the covariate-dependent scale and location parameters, respectively.

The dependence of the scale and location parameters on the covariate(s) could vary from linear to quadratic, to any form that results in the best fit to the data being studied with the integration of the covariate of interest. Numerous trials might be necessary to find the most optimum expressions for the parameters.

\section{B. Study Methodology}

Correlations are calculated between the historical rainfall intensity records of the station of interest and the climate oscillations known to affect the region. If the correlations are significant with a specific oscillation, the station's rainfall can potentially be predicted incorporating the oscillation index.

A typical IDF model is developed first using the chosen probability distribution function and estimating its parameters by optimizing the least square error. The next step is to test multiple variations of models incorporating the climate oscillation(s) and compare their goodness-of-fit in terms of least square error. The lower the least square error, the better the model fits the data.

\section{CASE STUdY}

\section{A. Data Description}

Precipitation data used in this study for Canada was obtained from the online Engineering Climate Dataset, which provided intensities of rainfall events with corresponding durations. The rainfall record for Rivere Heva starts at 1981 and ends at 1999. The rainfall intensities of the station correlate highly with the Atlantic Multidecadal Oscillation (AMO) and the Western Hemisphere Warm Pool (WHWP) indices.

\section{B. Typical IDF Model}

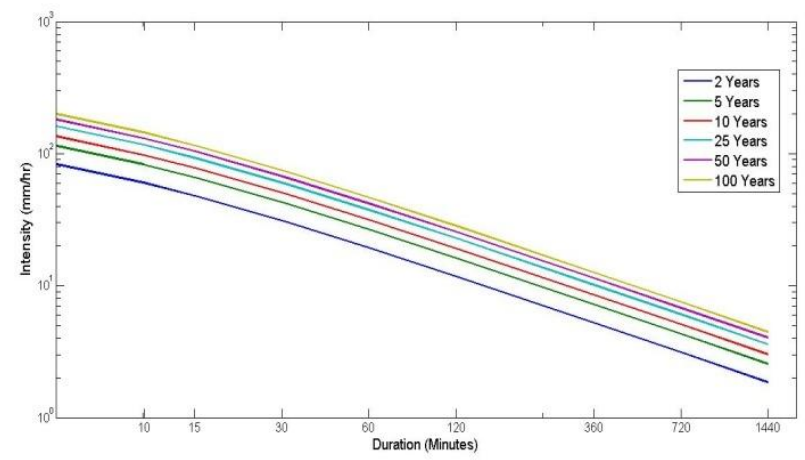

Fig. 1. Typical IDF curves for Riviere Heva. 
A typical IDF model is built using the Gumbel probability distribution function, as follows:

$$
i=5.9 \frac{3.3-\ln \left[-\ln \left(1-\frac{1}{T}\right)\right]}{(d+0.06)^{0.72}}
$$

The representation of the IDF curves of this relationship is shown in Fig. 1.

\section{IDF Model with Covariates of Climate Indices}

After testing multiple variations, the best model representing the rainfall intensities of Riviere Heva is found and expressed as follows:

$$
\begin{aligned}
& i=\exp \left(1.9+0.03 Y_{t 1}-0.51 Y_{t 1}^{2}+0.04 Y_{t 2}-0.001 Y_{t 2}^{2}\right) \\
& \frac{\left(2.74+0.18 Y_{t 1}-0.1 Y_{t 1}^{2}-0.11 Y_{t 2}+0.003 Y_{t 2}^{2}\right)}{(d+0.07)^{0.75}} \\
& \frac{-\ln \left[-\ln \left(1-\frac{1}{T}\right)\right]}{(d+0.07)^{0.75}}
\end{aligned}
$$

where $Y_{t 1}$ and $Y_{t 2}$ are the AMO and WHWP climate indices respectively.

Multiple graphs are needed to represent this relationship due to the inclusion of five variables. The duration is fixed in each graph, and curves are generated for each return period. Due to the inclusion of nine duration groups, there will be nine different graphs, each with a set of six curves. An example graph is given for a fixed duration of 5 minutes in Fig. 2.

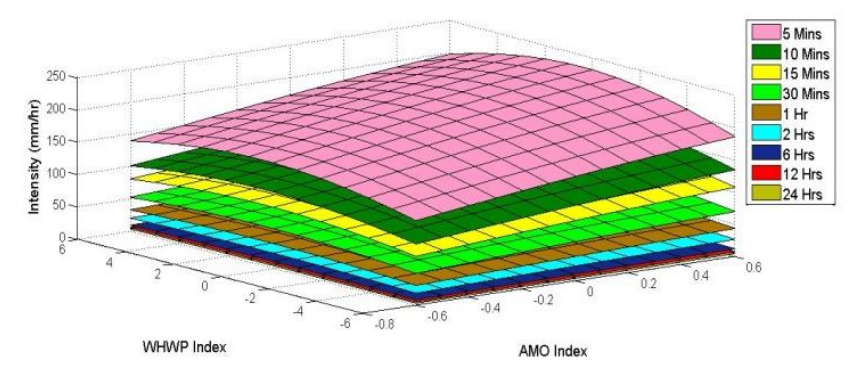

Fig. 2. IDF Curves with covariates of AMO and WHWP for Riviere Heva at fixed duration of 5 minutes.

The least square error value of the typical IDF relationship is 0.0185 , and for the IDF model with covariates the value is 0.0164 . The new model fits the data better than the typical one by $11.4 \%$, proving that IDF modeling with covariates has the potential to better project precipitation.

\section{CONCLUSION}

This paper gives a review on climate change and its link to precipitation. It highlights the importance of hydrology in the decision making process involved in water management. It discusses the importance of projecting extreme rainfall events using new modeling techniques.

A novel methodology for modeling IDF relationships using climate oscillations is presented and verified with a case study using rainfall intensity records for the station of Riviere Heva, Quebec, Canada. The new chosen model improves the goodness-of-fit significantly, proving that the new methodology should be considered for use in regions with climate oscillations known to impact their rainfall.

The findings of this study show that it is necessary to review and update IDF relationships in order to design water structures which will withstand future climate scenarios, and to achieve this end the testing of relationships with climate oscillations is a necessary step.

\section{ACKNOWLEDGMENT}

The authors of the paper thank Masdar Institute of Science and Technology and the Government of Abu Dhabi for providing the scholarship of Ms. Latifa A. Yousef. Data used in the present study to test the developed methodology was extracted from the website of Engineering Climate Dataset, which provides information that includes engineering climate data for Canada.

\section{REFERENCES}

[1] J. B. Smith, H.-J. Schellnhuber, M. M. Q. Mirza, S. Fankhauser, R Leemans, E. Lin, L. Ogallo, B. Pittock, R. Richels, and C. Rosenzweig, "Vulnerability to climate change and reasons for concern: a synthesis," Climate change, pp. 913-967, 2001.

[2] P. Lemke, R. Ren, and I. Alley, "The physical science basis. Contribution of Working Group I to the fourth assessment report of the Intergovernmental Panel on Climate Change," Climate Change 2007, Cambridge: Cambridge University Press, 2007, pp. 337-383.

[3] R. Ragab and C. Prudhomme, "Climate change and water resources management in arid and semi-arid regions: prospective and challenges for the 21st century," Biosystems Engineering, vol. 81, pp. 3-34, 2002.

[4] C. Pahl-Wostl, J. Sendzimir, P. Jeffrey, J. Aerts, G. Berkamp, and K. Cross, "Managing change toward adaptive water management through social learning," Ecology \& Society, vol. 12, 2007.

[5] J. Niemczynowicz, "Urban hydrology and water management present and future challenges," Urban Water, vol. 1, pp. 1-14, 1999.

[6] V. Nguyen, N. Desramaut, and T. Nguyen, "Estimation of urban design storms in consideration of GCM-based climate change scenarios," in Proc. International Conference on Water \& Urban Development Paradigms: Towards an Integration of Engineering, Design and Management Approaches, Leuven, 2008, pp. 347-356.

[7] H. Madsen, K. Arnbjerg-Nielsen, and P. S. Mikkelsen, "Update of regional intensity-duration-frequency curves in Denmark: Tendency towards increased storm intensities," Atmospheric Research, vol. 92, pp. 343-349, 2009.

[8] G. Mirhosseini, P. Srivastava, and L. Stefanova, "The impact of climate change on rainfall Intensity-Duration-Frequency (IDF) curves in Alabama," Regional Environmental Change, vol. 13, pp. 25-33, 2013.

[9] R. Rodríguez, X. Navarro, M. C. Casas, J. Ribalaygua, B. Russo, L. Pouget, and A. Redaño, "Influence of climate change on IDF curves for the metropolitan area of Barcelona (Spain)," International Journal of Climatology, vol. 34, pp. 643-654, 2014.

[10] N. Scafetta, "Empirical evidence for a celestial origin of the climate oscillations and its implications," Journal of Atmospheric and Solar-Terrestrial Physics, vol. 72, pp. 951-970, 2010.

[11] M. Dima and G. Lohmann, "A hemispheric mechanism for the Atlantic multidecadal oscillation," Journal of Climate, vol. 20, 2007.

[12] C. F. Ropelewski and M. S. Halpert, "North American Precipitation and Temperature Patterns Associated with the El Niño/Southern Oscillation (ENSO)," Monthly Weather Review, vol. 114, pp. 2352-2362, 1986.

[13] G. M. MacDonald and R. A. Case, "Variations in the Pacific Decadal Oscillation over the past millennium," Geophysical Research Letters, vol. 32, 2005.

[14] H. Middelkoop, K. Daamen, D. Gellens, W. Grabs, J. C. Kwadijk, H Lang, B. W. Parmet, B. Schädler, J. Schulla, and K. Wilke, "Impact of climate change on hydrological regimes and water resources 
management in the Rhine basin," Climatic Change, vol. 49, pp. 105-128, 2001

[15] N. S. Christensen, A. W. Wood, N. Voisin, D. P. Lettenmaier, and R. N. Palmer, "The effects of climate change on the hydrology and water resources of the Colorado River basin," Climatic Change, vol. 62, pp 337-363, 2004

[16] A. Werritty, "Living with uncertainty: climate change, river flows and water resource management in Scotland," Science of the Total Environment, vol. 294, pp. 29-40, 2002.

[17] M. B. Charlton and N. W. Arnell, "Adapting to climate change impacts on water resources in England - An assessment of draft wate resources management plans," Global Environmental Change, vol. 21, pp. 238-248, 2011.

[18] C. Pahl-Wostl, "Transitions towards adaptive management of water facing climate and global change," Water Resources Management, vol. 21, pp. 49-62, 2007.

[19] M. Beniston, M. Stoffel, M. Hill Clarvis, and P. Quevauviller, "Assessing climate change impacts on the quantity of water in Alpine regions: Foreword to the adaptation and policy implications of the EU/FP7 'ACQWA' project," Environmental Science \& Policy, 2014.

[20] D. Koutsoyiannis and G. Baloutsos, "Analysis of a long record of annual maximum rainfall in Athens, Greece, and design rainfall inferences," Natural Hazards, vol. 22, pp. 29-48, 2000.

[21] G. A. Meehl, F. Zwiers, J. Evans, T. Knutson, L. Mearns, and P. Whetton, "Trends in extreme weather and climate events: Issues related to modeling extremes in projections of future climate change," Bulletin of the American Meteorological society, vol. 81, pp. 427-436, 2000.

[22] K. Hennessy, J. Gregory, and J. Mitchell, "Changes in daily precipitation under enhanced greenhouse conditions," Climate Dynamics, vol. 13, pp. 667-680, 1997.

[23] R. Higgins, J. E. Schemm, W. Shi, and A. Leetmaa, "Extreme precipitation events in the western United States related to tropical forcing," Journal of Climate, vol. 13, pp. 793-820, 2000.

[24] C. Jones, "Occurrence of extreme precipitation events in California and relationships with the Madden-Julian Oscillation," Journal of Climate, vol. 13, 2000.

[25] V. V. Kharin, F. W. Zwiers, X. Zhang, and G. C. Hegerl, "Changes in temperature and precipitation extremes in the IPCC ensemble of global coupled model simulations," Journal of Climate, vol. 20, 2007.

[26] K. Tank, T. Peterson, D. Quadir, S. Dorji, X. Zou, H. Tang, K. Santhosh, U. Joshi, A. Jaswal, and R. Kolli, "Changes in daily temperature and precipitation extremes in central and south Asia," Journal of Geophysical Research: Atmospheres (1984-2012), vol. 111, 2006.

[27] P. Willems, K. Arnbjerg-Nielsen, J. Olsson, and V. Nguyen, "Climate change impact assessment on urban rainfall extremes and urban drainage: Methods and shortcomings," Atmospheric Research, vol. 103, pp. 106-118, 2012

[28] M. Grum, A. Jorgensen, R. Johansen, and J. Linde, "The effect of climate change on urban drainage: an evaluation based on regional climate model simulations," Water Science \& Technology, vol. 54, pp. 9-15, 2006

[29] R. P. Allan and B. J. Soden, "Atmospheric warming and the amplification of precipitation extremes," Science, vol. 321, pp. 1481-1484, 2008

[30] G. Lenderink and E. van Meijgaard, "Increase in hourly precipitation extremes beyond expectations from temperature changes," Nature Geoscience, vol. 1, pp. 511-514, 2008.

[31] M. M. Bernard, "Formulas for rainfall intensities of long duration," Transactions of the American Society of Civil Engineers, vol. 96, pp. 592-606, 1932
[32] R. H. Frederick, V. A. Myers, and E. P. Auciello, Five-to 60-Minute Precipitation Frequency for the Eastern and Central United States: National Weather Service, Office of Hydrology, 1977.

[33] J. Bougadis and K. Adamowski, "Scaling model of a rainfall intensity-duration-frequency relationship," Hydrological Processes, vol. 20, pp. 3747-3757, 2006.

[34] A. Langousis and D. Veneziano, "Intensity-duration-frequency curves from scaling representations of rainfall," Water Resources Research vol. 43, 2007.

[35] I. H. Elsebaie, "Developing rainfall intensity-duration-frequency relationship for two regions in Saudi Arabia," Journal of King Saud University - Engineering Sciences, vol. 24, pp. 131-140, 2012.

[36] D. Koutsoyiannis, D. Kozonis, and A. Manetas, "A mathematical framework for studying rainfall intensity-duration-frequency relationships," Journal of Hydrology, vol. 206, pp. 118-135, 1998

[37] T. A. Endreny and N. Imbeah, "Generating robust rainfall intensity-duration-frequency estimates with short-record satellite data," Journal of Hydrology, vol. 371, pp. 182-191, 2009.

[38] S. El Adlouni and T. B. Ouarda, "Joint Bayesian model selection and parameter estimation of the generalized extreme value model with covariates using birth-death Markov chain Monte Carlo," Water Resources Research, vol. 45, 2009.

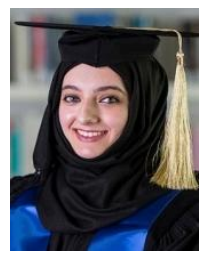

Latifa A. Yousef was born in England on October 13 1990. Yousef obtained a bachelor's degree in civil and environmental engineering from the University of Sharjah, Sharjah, United Arab Emirates, and graduated in June 2014 with a master's degree in water and environmental engineering, with a focus on statistical hydrology, from Masdar Institute of Science and Technology.

She is currently employed as a research assistant at Masdar Institute of Science and Technology, working in the iWater center under the supervision of Prof. Taha B. M. J. Ouarda. She completed a summer internship at Parsons Inc. in their Dubai, United Arab Emirates office in the year 2011.

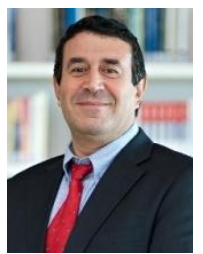

Taha B. M. J. Ouarda specializes in hydrometeorology, environmental and public health modeling, and risk analysis. Prior to joining Masdar Institute, Mr. Ouarda was the chairman of the Canada Research Chair on the estimation of hydro-meteorological variables, and also the chairman of the Industrial Chair in statistical hydrology, where his research team represented one of the largest Canadian teams in the field of hydrology. Mr. Ouarda has also served as the president of the National Canadian Committee on Statistical Hydrology.

Mr. Ouarda holds a $\mathrm{PhD}$ degree in civil engineering from Colorado State University. He has developed several approaches for the estimation of extreme hydro-meteorological events on local and regional scales, developed several methodologies for the modeling of hydro-meteorological variables under changing environments, and developed several computer softwares that deal with a range of problems in the fields of water resources and environmental engineering. He has also led several international projects dealing with hydro-meteorological modeling, environmental analysis and the links between climate evolution, the environment, and public health

Mr. Ouarda is the recipient of a number of prestigious awards and is a member of the editorial board of a number of international scientific journals such as the Journal of Hydrology and the Hydrological Sciences Journal. 